\title{
openheart Ultrathin-strut biodegradable polymer versus durable polymer drug-eluting stents: a meta-analysis
}

\author{
Mohammad Riashad Monjur (D) , ${ }^{1,2}$ Christian F Said, ${ }^{1}$ Paul Bamford, ${ }^{1,2}$ \\ Michael Parkinson, ${ }^{1}$ Richard Szirt, ${ }^{3}$ Thomas Ford (ib) ${ }^{1,2,4}$
}

To cite: Monjur MR, Said CF, Bamford P, et al. Ultrathin-strut biodegradable polymer versus durable polymer drug-eluting stents: a meta-analysis. Open Heart 2020;7:e001394. doi:10.1136/ openhrt-2020-001394

Received 19 July 2020 Revised 3 September 2020 Accepted 9 September 2020

Check for updates

(c) Author(s) (or their employer(s)) 2020. Re-use permitted under CC BY-NC. No commercial re-use. See rights and permissions. Published by BMJ.

${ }^{1}$ Department of Cardiology, Central Coast Local Health District, Gosford, New South Wales, Australia

${ }^{2}$ Faculty of Health and Medicine, The University of Newcastle, Callaghan, New South Wales, Australia

${ }^{3}$ Department of Cardiology, St George Hospital, Sydney, New South Wales, Australia

${ }^{4}$ Institute of Cardiovascular and Medical Sciences, University of Glasgow, Glasgow, UK

Correspondence to DrThomas Ford; tom.ford@ health.nsw.gov.au

\section{ABSTRACT}

Objectives Determine whether an ultrathin biodegradable polymer sirolimus-eluting stent ('Orsiro'-BP-SES) has clinical benefits over second-generation durable polymer drug-eluting stents (DP-DES).

Methods We conducted a prospective systematic review and meta-analysis of randomised clinical trials comparing Orsiro BP-SES against DP-DES (PROSPERO Registration: CRD42019147136). The primary outcome was target lesion failure (TLF): composite of cardiac death, target vessel myocardial infarction (TVMI) and clinically indicated target lesion revascularisation (TLR)) evaluated at the longest available follow-up.

Results Nine trials randomised 11302 patients to either Orsiro BP-SES or DP-DES. At mean weighted follow-up of 2.8 years, the primary outcome (TLF) occurred in 501 of 6089 (8.2\%) participants with BP-SES compared with 495 of $5213(9.5 \%)$ participants with DP-DES. This equates to an absolute risk reduction of $1.3 \%$ in TLF in favour of Orsiro BP-SES (OR 0.82; $95 \% \mathrm{Cl} 0.69$ to 0.98 ; $\mathrm{p}=0.03$ ). This was driven by a reduction in TVMI (OR 0.80 ; $95 \% \mathrm{Cl} 0.65$ to $0.98 ; p=0.03)$. There were no significant differences in other clinical endpoints: cardiac death, TLR and stent thrombosis.

Conclusion The Orsiro BP-SES shows promising clinical outcomes in patients undergoing percutaneous coronary intervention compared with contemporary secondgeneration DES at a short to medium term follow-up. More research is warranted to evaluate performance over a longer follow-up period and in different clinical and lesion subsets.

\section{INTRODUCTION}

Contemporary second-generation durable polymer drug-eluting stents (DP-DES) have proven safety resulting in excellent clinical outcomes following percutaneous coronary intervention (PCI). ${ }^{1}{ }^{2}$ Historical concerns from first-generation DES regarding the effects of durable polymer on delayed vessel healing and peristrut inflammation drove stent iterations incorporating biodegradable polymer sirolimus-eluting stents (BP-SES) with thinner struts. ${ }^{34}$ Indeed, thinner stent strut designs have recently been shown to reduce in-stent restenosis and target lesion

\section{Key questions}

What is already known about this subject?

- Recent randomised trials support non-inferiority of Orsiro ultrathin-strut biodegradable polymer sirolimus-eluting stent (BP-SES) compared with contemporary durable polymer drug-eluting stents (DP-DES).

What does this study add?

- Patients randomised to percutaneous coronary intervention with Orsiro ultrathin-strut BP-SES had almost one-fifth less target lesion failure compared with contemporary DP-DES at mean follow-up of 2.8 years. This was largely due to a significant reduction in target vessel myocardial infarction. There were no differences in other clinical and safety endpoints between the two group: cardiac death, target lesion revascularisation and stent thrombosis.

How might this impact on clinical practice?

- Ultrathin-strut BP-SES designs may further improve clinical outcomes over contemporary secondgeneration durable polymer DES. Future research is warranted with more randomised trials powered to compare modern generation stent platforms focusing on utility in different patient subgroups.

revascularisation (TLR) in a pooled metaanalysis. $^{5}$

The Orsiro BP-SES (BIOTRONIK, Buelach, Switzerland) has gained significant traction as one such ultrathin strut $(60 \mu \mathrm{m}$ in stents $<3.0 \mathrm{~mm}$ diameter) sirolimus-eluting stent with a large clinical evidence base in contemporary studies. ${ }^{4-8}$ Many studies have shown non-inferiority of the Orsiro when compared with DP-DES, however, recent data from BIOFLOW $\mathrm{V}$ and BIOSTEMI studies support lower target lesion failure (TLF) in patients randomised to the Orsiro BP-SES over DP-DES. ${ }^{9}{ }^{10}$ In light of the evolving evidence base, we performed a prospective meta-analysis of randomised controlled trials (RCTs) comparing Orsiro BP-SES versus DP-DES. 


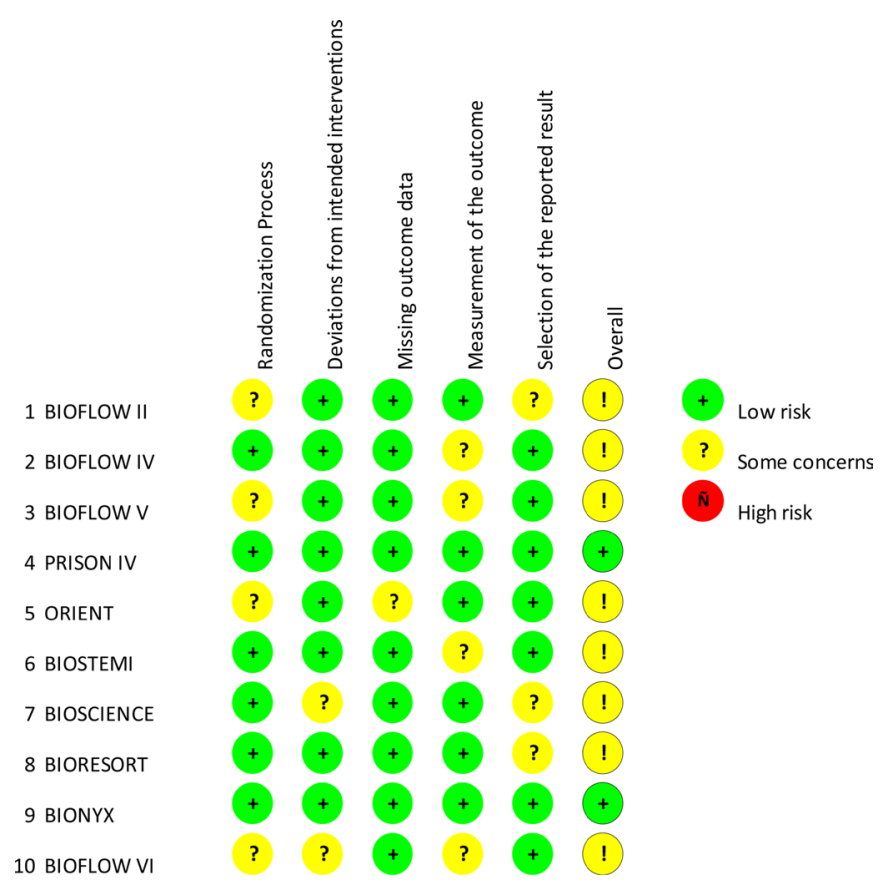

Figure 1 Risk-of-bias summary for trials included in the meta-analysis.

\section{METHODS}

The data, analytical methods and study materials have been made available to other researchers for the purposes of reproducing the results or replicating the procedure. The full study protocol was registered with the International Database of Prospectively Registered Systematic Reviews in Health and Social care

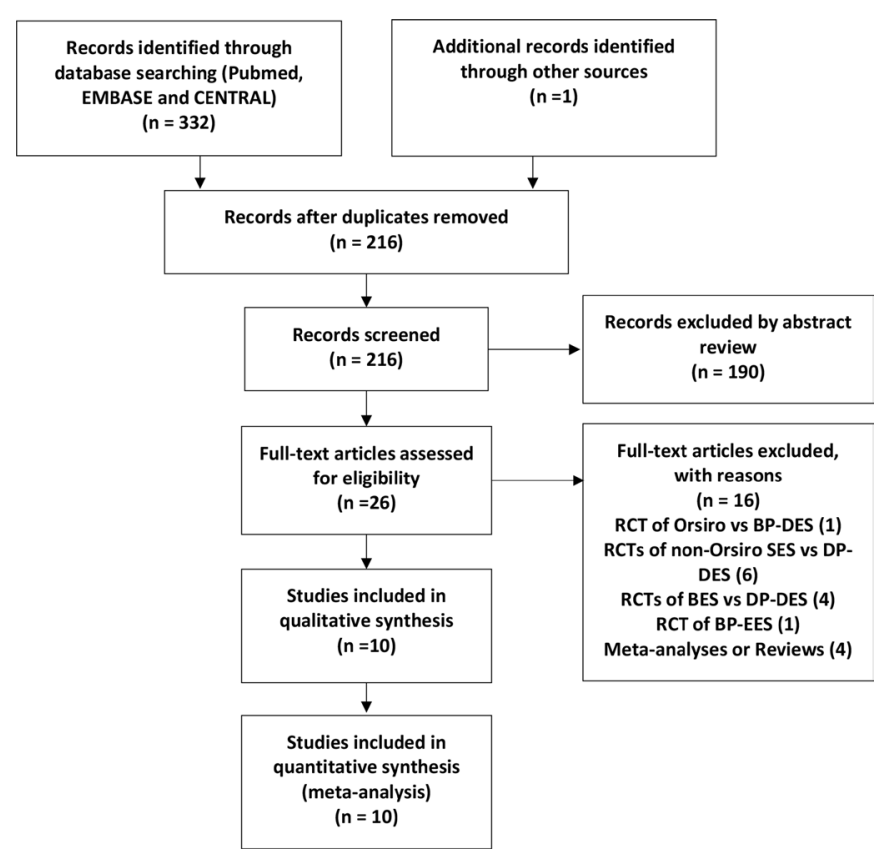

Figure 2 PRISMA flow chart for studies included in the meta-analysis. BP-EES, biodegradable polymer everolimuseluting stent; DP-DES, durable polymer drug-eluting stents; PRISMA, Preferred Reporting Items for Systematic Reviews and Meta-Analyses; RCT, randomised controlled trial; SES, sirolimus-eluting stent.
(PROSPERO-CRD42019147136) and data is made available within this manuscript. This study was performed according to the Preferred Reporting Items for Systematic reviews and Meta-Analyses guidelines. ${ }^{11}$ Patients or the public were not involved in the design, conduct, reporting or dissemination plans of our research.

\section{Eligibility criteria}

The inclusion criteria for the studies in our meta-analysis were as follows: RCTs comparing the Orsiro ultrathin strut, biodegradable polymer, sirolimus-eluting stents versus durable polymer second-generation drug-eluting stents, irrespective of the specific antiproliferative drug, with the availability of clinical or angiographic follow-up. Data on TLF had to be available in the publication or authors were approached for this data. Publications were excluded if they only compared two biodegradable polymer stents to each other and, for the biodegradable arm, were non-sirolimus eluting or had a strut other than an ultrathin strut. To minimise heterogeneity, we included only the studies that used the Orsiro BP-SES. Non-randomised trials, publications not in English and those with outcomes of interest less than 12 months follow-up were excluded.

\section{Quality assessment}

Two reviewers (CFS and MP) independently performed the risk-of-bias assessment of the included trials using the Cochrane Collaboration framework: bias arising from the randomisation process, bias due to deviation from intended intervention, bias due to missing outcome data, bias in measurement of the outcome and bias in selection of the reported results. Discrepancies were resolved by consensus with a third independent reviewer (TF). The risk-of-bias summary according to the risk-ofbias tool of the Cochrane collaboration framework is provided (figure 1). We planned to assess publication bias according to funnel plot asymmetry using standard error as the measure of study size and OR of treatment effect if we yielded over 10 studies. ${ }^{12}$

\section{Search strategy}

A systematic search of online databases of PubMed, EMBASE and Cochrane Central Register of Controlled Trials was performed until 26 August 2020. Peer-reviewed RCTs were selected using combinations of keywords, and their variations, pertinent to our intervention of interest and comparison with 'biodegradable polymer', 'drugeluting stent', 'sirolimus', 'orsiro', 'durable polymer', 'everolimus' and 'zotarolimus'. Two reviewers (MRM and CFS) independently screened abstracts against the inclusion and exclusion criteria while reference lists of relevant articles and previous meta-analyses were reviewed to identify other relevant studies. They then screened the full text of potentially relevant trials. Disagreements were resolved by consensus involving a third reviewer (PB). Conference abstracts from major cardiology scientific sessions were searched for completeness. 
Table 1 Baseline characteristics of included trials

\begin{tabular}{|c|c|c|c|c|c|c|c|}
\hline \multirow[b]{2}{*}{ Study } & \multirow[b]{2}{*}{ Year } & \multirow[b]{2}{*}{$\mathbf{N}$} & \multirow{2}{*}{$\begin{array}{l}\text { Duration } \\
\text { (years) }\end{array}$} & \multicolumn{2}{|c|}{ BP-SES } & \multicolumn{2}{|l|}{ DP-DES } \\
\hline & & & & Stent & $\mathbf{N}$ & Stent & $\mathbf{N}$ \\
\hline Bio-Resort & 2019 & 2342 & 3 & Orsiro & 1169 & Resolute Integrity (ZES) & 1173 \\
\hline BIOFLOW IV & 2019 & 575 & 1 & Orsiro & 385 & XIENCE (EES) & 190 \\
\hline BIOFLOW V & 2020 & 1334 & 3 & Orsiro & 884 & XIENCE (EES) & 450 \\
\hline BIONYX & 2020 & 2488 & 2 & Orsiro & 1245 & Resolute Onyx (ZES) & 1243 \\
\hline BIOSCIENCE & 2018 & 2119 & 5 & Orsiro & 1063 & XIENCE (EES) & 1056 \\
\hline BIOFLOW II & 2018 & 452 & 5 & Orsiro & 298 & XIENCE (EES) & 154 \\
\hline ORIENT & 2019 & 372 & 3 & Orsiro & 250 & Resolute Integrity (ZES) & 122 \\
\hline PRISON IV & 2017 & 330 & 1 & Orsiro & 165 & XIENCE (EES) & 165 \\
\hline
\end{tabular}

BP-SES, biodegradable polymer sirolimus-eluting stent; DP-DES, durable polymer drug-eluting stents; EES, everolimus-eluting stents; ZES, zotarolimus-eluting stents.

\section{Outcomes and definitions}

The primary outcome was TLF. TLF was defined as a composite index of cardiac death, target vessel myocardial infarction (TVMI) and clinically indicated TLR. Secondary outcomes included cardiac death, TVMI, clinically indicated TLR and definite or probable stent thrombosis (ST). Definite or probable ST was determined according to the academic research consortium definition. ${ }^{13}$ Outcomes data were extracted by two independent authors (MRM and RS). Differences in opinion were resolved by consensus involving a third reviewer (TF).

\section{Data and statistical analysis}

Follow-up duration was calculated as mean weighted duration according to study size. Pooled mean data were used to compare procedural aspects between the groups using an unpaired t-test. The study hypothesis was prespecified and tested with a two-tailed alpha of 0.05 .

The statistical analysis was performed using R V 4.0 using the metaphor package ${ }^{14}$ and RevMan V 5.3.5 (the Cochrane Collaboration). Analyses for all outcomes were done on an intention-to-treat basis. The randomeffects method was selected on account of inherent heterogeneity related to the different types of stents and patient or lesion types enrolled. We also performed a fixed-effect (Mantel-Haenszel) approach for completeness. We summarised the estimate of effect incorporating the clinical outcomes as OR with 95\% CIs for our dichotomous data. Prespecified meta-regression was performed to assess the interaction between acute coronary syndrome (ACS) presentation and the primary endpoint. A leave-one-out sensitivity analysis was performed by iteratively removing one study at a time to assess whether any single study was driving our findings. Heterogeneity testing with Higgins $\mathrm{I}^{2}$ was performed with a threshold of $>50 \%$ taken as evidence of significant heterogeneity between studies. ${ }^{15}$ To assess the risk of type I and II errors, we conducted a trial sequential analysis (TSA) to calculate the required information size which is a summation of sample sizes from a given number of included trials, $5 \%$ overall type I error and power of $80 \% .^{16}$

\section{RESULTS}

\section{Study selection and characteristics}

An initial search yielded 332 citations. Applying inclusion criteria defined in the methods, we evaluated 45 abstracts of which we assessed 26 full-text publications with the longest available follow-up. The search flow diagram can be found in figure 2. Nine randomised trials met the inclusion criteria and reported primary outcome of TLF follow-up of 12 months or greater. ${ }^{10}$ 17-26

All trials included were published between 2017 to 2020. Nine trials randomised 11302 patients to either Orsiro BP-SES or DP-DES. The mean weighted follow-up for the included studies was $2.8 \pm 1.4$ years (table 1$)$. The DP-DES included everolimus-eluting stents (6 trials) and zotarolimus-eluting stents (3 trials). A total of 6089 patients were randomised to BP-SES strategy and 5213 patients to the DP-DES strategy. The mean age of the population was $64.2 \pm 1.0$ years with baseline patient characteristics shown in table 2. Risk-of-bias and quality of evidence assessment is summarised in figure 1.

\section{Efficacy outcome: TLF}

There was a statistically significant reduction in the primary outcome (TLF) among patients randomised to Orsiro BP-SES $(501 / 6089(8.2 \%))$ compared with DP-DES (495/5213 (9.5\%); OR 0.82; $95 \%$ CI 0.69 to 0.98 ; $\mathrm{p}=0.037)$. The outcomes from the analysis are summarised in table 3 and figure 3. Forrest plots are summarised in figure 4. Our findings remained significant using the Mantel-Haenszel fixed effects model (OR 0.86; 95\% CI 0.75 to $0.98, \mathrm{p}=0.02$ ). The key findings of the study are provided in a visual summary (figure 5 . 


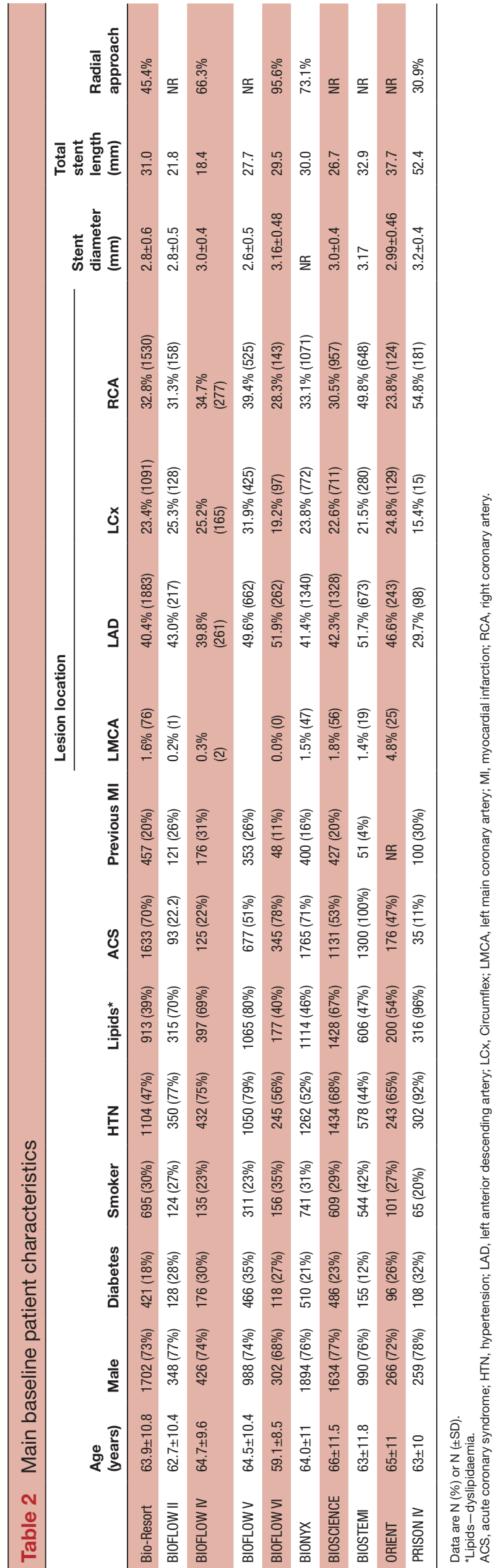

Safety endpoints: TVMI, cardiac death, TLR and ST

Safety endpoints were reported in all studies. TVMI occurred in 201 of 5832 participants $(3.4 \%)$ randomised to the Orsiro BP-SES group and 203 of 5088 participants $(4.0 \%)$ randomised to the DP-DES group. This was a statistically significant reduction in TVMI with BP-SES over DP-DES (OR 0.80; 95\% CI 0.65 to $0.98 ; \mathrm{p}=0.03$ ). Other safety endpoints were not statistically different between the groups: Cardiac death $(2.7 \%$ vs $2.9 \%$; OR 1.01 (95\% CI 0.80 to 1.27$)$; $\mathrm{p}=0.92$ ), clinically driven TLR ( $4.5 \%$ vs $5.2 \%$; OR 0.85 (95\% CI 0.64 to 1.14 ); $\mathrm{p}=0.28$ ) and ST $(1.8 \%$ vs $2.2 \%$; OR 0.87 (95\% CI 0.55 to 1.37$)$; $\mathrm{p}=0.54)$.

\section{Meta-regression}

There was no statistically significant interaction between ACS and treatment effect (TLF) at study level between the groups $(\mathrm{OR}=0.983$ (per $10 \%$ increase in ACS) $(95 \% \mathrm{CI}$ 0.898 to 1.077$) ; \mathrm{p}=0.626$; figure 6 )) .

\section{Sensitivity analyses and TSA}

Our findings for both leave-one-out sensitivity analyses and TSA are provided in the online supplemental appendix. Our sensitivity analysis showed that TLF remained significant after excluding BIOSCIENCE which reduced our pooled TLF by $10.4 \%$ (OR $0.773,95 \%$ CI 0.646 to $0.926 ; \mathrm{p}=0.005$ ). Excluding any of the other studies resulted in an insignificant result between the two arms with the highest trend towards an increase in TLF of $7.1 \%$ after excluding BIOFLOW V (OR 0.912, 95\% CI 0.787 to $1.058 ; \mathrm{p}=0.223$ ). The TSA, however, suggested more trials are needed to achieve the required power for a conclusive meta-analysis.

\section{DISCUSSION}

In this meta-analysis of randomised trials comparing the Orsiro BP-SES and contemporary DP-DES, we found TLF to be significantly lower in participants randomised to the Orsiro BP-SES at a weighted average follow-up of 2.8 years after PCI. There was a similar difference in TVMI but remaining clinical outcomes of cardiac mortality, clinically driven TLR and ST were similar between the two groups.

The most striking finding of reduction in TLF in favour of Orsiro BP-SES is noteworthy but requires careful consideration. Previous studies have reported similar directional trends without establishing statistical significance. $^{6-8}$ However, the data from three recent trials (BIOSTEMI, BIOFLOW IV and BIOFLOW VI) and longer-term outcomes of trials (BIOFLOW II 5 years outcomes, BIOSCIENCE 5 years outcomes, BIO-RESORT 3 years outcomes, BIOFLOWV 3 years outcomes, ORIENT 3 years outcomes and BIONYX 2 years outcomes) together support a significant reduction in the odds of TLF for Orsiro BP-SES when compared with DP-DES (absolute risk reduction of $1.3 \%$ ). This is driven predominantly by the significant reduction in TVMI in Orsiro BP-SES 
Table 3 Odds ratios comparing clinical outcomes for Orsiro BP-SES and DP-DES

\begin{tabular}{lllllll}
\hline & Orsiro BP-SES, \% & DP-DES, \% & OR & 95\% CI & P value \\
\hline Target lesion failure & 8.2 & 9.5 & 0.82 & 0.69 to 0.98 & 0.03 \\
\hline Target vessel myocardial infarction & 3.4 & 4.0 & 0.80 & 0.65 to 0.98 & 0.03 \\
Cardiac mortality & 2.7 & 2.9 & 1.01 & 0.80 to 1.27 & 0.92 \\
Stent thrombosis & 1.8 & 2.2 & 0.87 & 0.55 to 1.37 & 0.54 \\
Clinically driven target lesion revascularisation & 4.5 & 5.2 & 0.85 & 0.64 to 1.14 & 0.28 \\
\hline
\end{tabular}

BP-SES, biodegradable polymer sirolimus-eluting stent; DP-DES, durable polymer drug-eluting stents.

patients as the remaining components of the composite index were similar between groups. This may relate to potential advantages of ultrathin strut stents in the treatment of small vessel coronary artery disease (as suggested by subgroup analysis in BIO-RESORT) compared with its other attributes including the polymer location, degradation time of the polymer, the antiproliferation agent and the drug-elution kinetics. ${ }^{27}$

There are two possible stent factors which could explain our findings. The first and most pertinent stent factor that may explain reduction in TLF and TVMI is the ultrathin strut stent design of the ORSIRO stent. Both the DP-DES have thicker struts (XIENCE $=81 \mu \mathrm{m}$ and RESOLUTE $=91 \mu \mathrm{m}$ ) compared with Orsiro BP-SES 'ultrathin' strut $(60 \mu \mathrm{m}$ in stents $<3.0 \mathrm{~mm}$ in diameter and $>80 \mu \mathrm{m}$ in stents $>3.0 \mathrm{~mm}$ ). Previous meta-analysis looking at all-comer ultrathin strut stents versus DP-DES have hinted at benefit in favour of the ultra-thin strut design. ${ }^{5}$ Thinner struts lead to greater flexibility and deliverability but crucially may be less traumatic to the endothelium and reduce perivascular inflammation promoting better endothelial coverage. Furthermore, they may be less likely to disturb flow in side branches and may decrease stent thrombogenicity with reduced detrimental low shear stress forces post deployment. ${ }^{28} 29$ These beneficial effects of thinner struts are likely to be enhanced and more favourable in smaller vessels (BIORESORT- subgroup analysis).

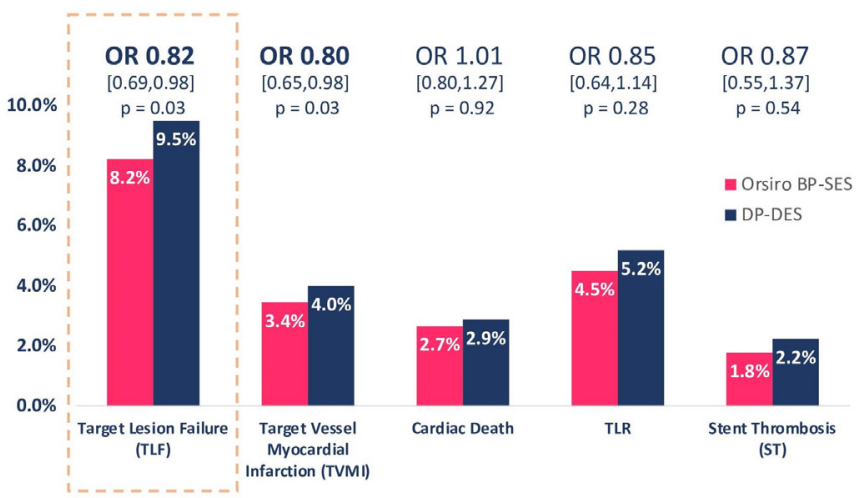

Figure 3 Target lesion failure and secondary end points. BP-SES, biodegradable polymer sirolimus-eluting stent; DPDES, durable polymer drug-eluting stents; TLR, target lesion revascularisation.

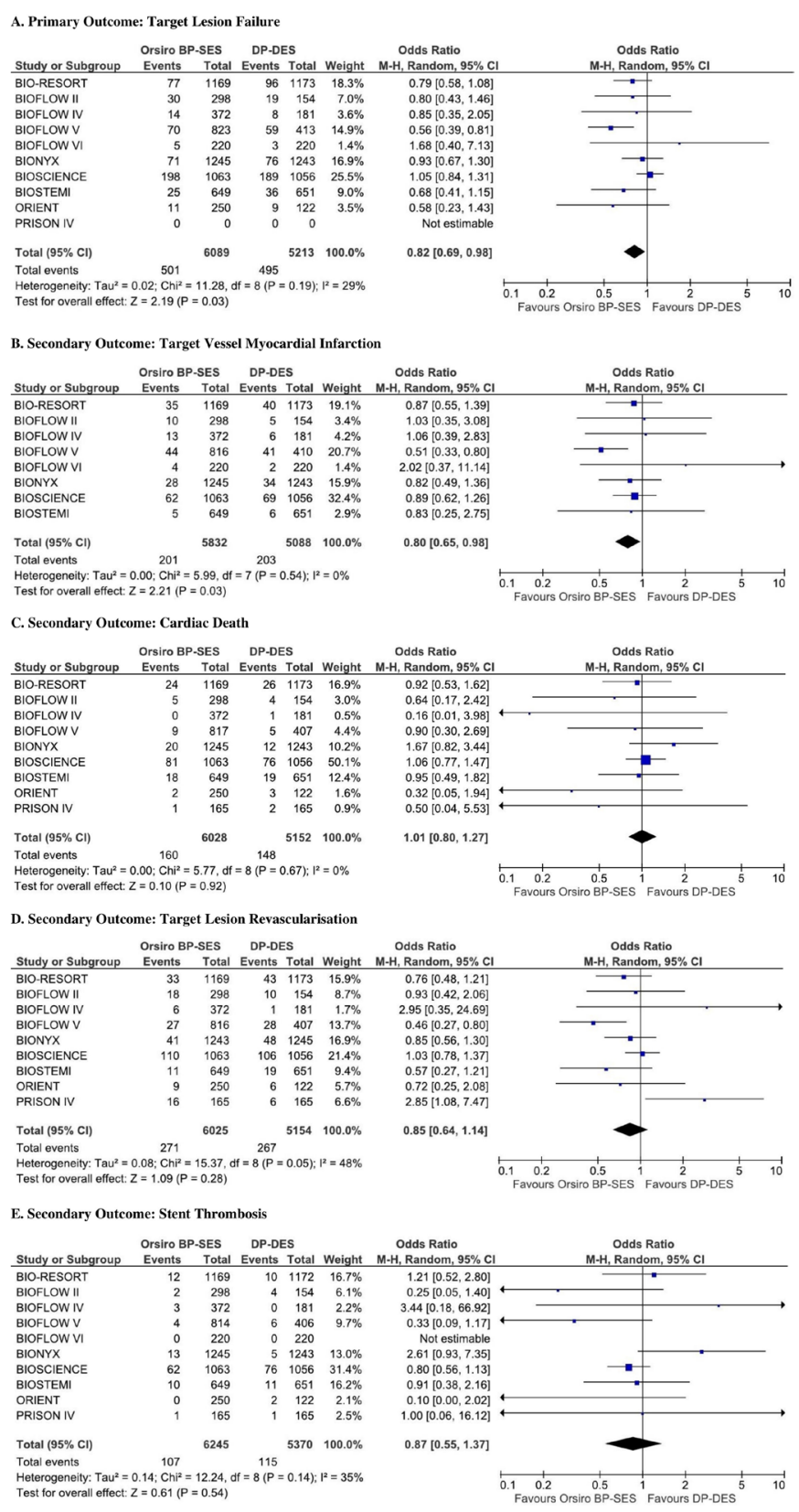

Figure 4 Forest plots of primary outcome (A) and secondary outcomes (B-E) for Orsiro BP-SES versus DPDES. BP-SES, biodegradable polymer sirolimus-eluting stent; DP-DES, durable polymer drug-eluting stents. 
Orsiro vs Second Generation Durable Polymer Drug Eluting Stents (DP-DES)

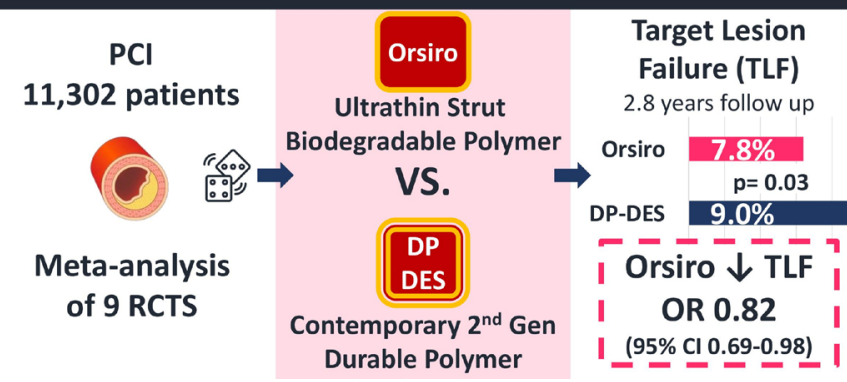

Figure 511302 participants randomised across 9 RCTs between the Orsiro BP-SES and DP-DES groups showed a significant reduction in TLF in participants with the Orsiro BP-SES. BP-SES, biodegradable polymer sirolimus-eluting stent (Odds ratio 0.82; 95\% $\mathrm{Cl} 0.69-0.98 ; \mathrm{P}=0.03$ ); DP-DES, durable polymer drug-eluting stents; RCTs, randomised controlled trials; TLF, target lesion failure.

Second, the reduction in TLF seen may be attributable to the more biocompatible biodegradable polymer. The biodegradable polymer matrix of poly-L lactic acid in the Orsiro BP-SES degrades after 12-24 months. While previous meta-analyses included studies with shorter term follow-ups, our mean follow-up was 2.8 years and six out of the nine studies in our TLF analysis reported outcomes at 24 months or more. This finding is novel and one provocative interpretation is reduction in TLF accrues related to better endothelialisation over the thinner struts assisted by polymer degradation. ${ }^{30}$ Concern about longer-term events with durable polymers are largely historical and were considered related to by-products of first generation DES polymer degradation implicated with immunogenicity and vascular inflammation. ${ }^{9}$ Crucially, however, no

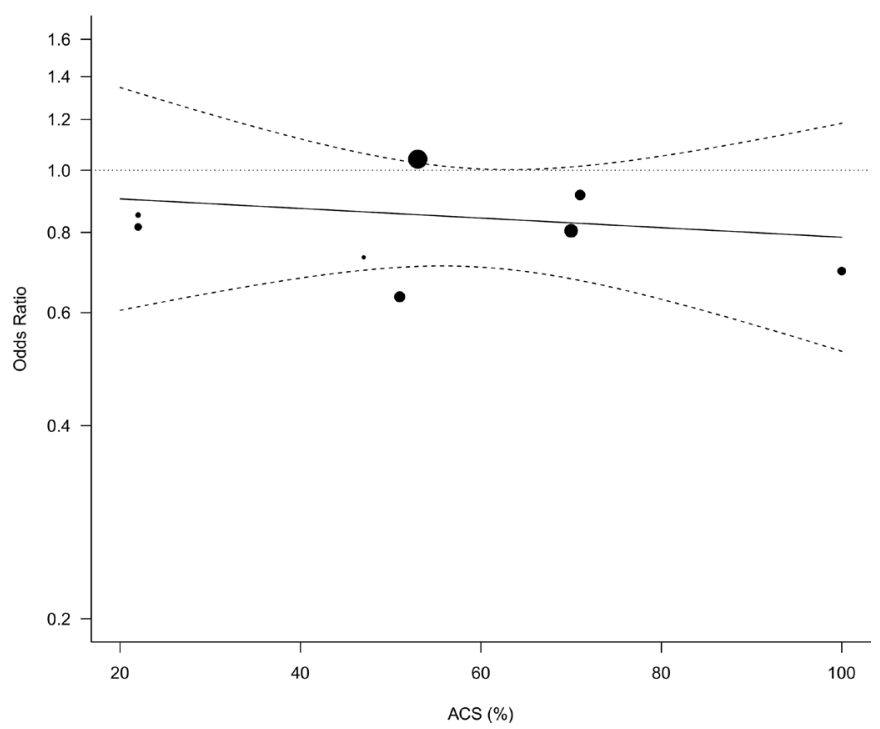

Figure 6 Interaction of ACS and treatment effect (TLF) at study level between BP-SES and DP-DES groups. ACS, acute coronary syndrome; BP-SES, biodegradable polymer sirolimus-eluting stent; DP-DES, durable polymer drugeluting stents; TLF, target lesion failure. superiority has been noted in other trials of non-ultrathin BP SES versus DP-DES. ${ }^{31}$

TVMI reflects reinfarction of the stented vessel including both peri-procedural myocardial infarction and spontaneous myocardial infarction. From the data presented, it was impossible to distinguish between these important types of myocardial infarction. Recent debate in the cardiovascular community ${ }^{32}$ has highlighted the importance of distinguishing between procedural and spontaneous MI and this may have helped us to characterise further important differences between the groups. If the primary outcome difference was driven by periprocedural events then this is less meaningful for patient care given that spontaneous myocardial infarcts are more strongly linked with major adverse cardiovascular events (including death) compared with periprocedural myocardial infarctions. ${ }^{33}$ It is most likely that the ultrathin design of the Orsiro BP-SES $(<3 \mathrm{~mm})$ contributed to reduced periprocedural MI via reduced side branch coverage, rather than the biodegradable polymer, to result in the reduced TVMI, the primary driver of the superior TLF. ${ }^{534}$

Subgroup analysis of participants with ACS did not show any significant effect on TLF which may relate to a lack of power from use of study-level rather than individual patient level data. ACS patients should be identified as a key research group of interest given the BIOSTEMI study and inferences from directional trend in our meta-regression . BIOSTEMI and the STEMI subgroup in BIOSCIENCE trial both had a stronger trend towards reduced TLF in ACS which could signal benefit of thinner struts in the setting of prothrombotic milieu.

Although all studies which reported TLF demonstrated a numerical trend towards a reduction in TLF, the finding was driven predominantly by one study (BIOFLOW V). Our results contrast with previous meta-analyses that show no difference in TLF, or any of the secondary outcomes, between the Orsiro BP-SES and DP-DES. ${ }^{6} 8$ Our findings are, thus, novel and consistent with result of longer-term follow-up studies of Orsiro in addition to the recent BIOFLOW V trial.

\section{Limitations}

There are several limitations to this work. First, four of the trials had short 1-year follow-up. Whether the outcomes seen persist in the longer term after the complete degradation of the polymer is unknown. Second, our metaanalysis was limited to aggregate study-level comparison which provides a less comprehensive comparison than patient-level data. The latter would have increased the power to detect interaction of treatment effect according to key subgroups (ACS or small vessels). Our metaregression analysis did not show an effect signal for ACS but was underpowered to provide a definitive conclusion on subgroups. A recent patient-level meta-analysis of four of the included trials (BIOFLOW II, BIOFLOW IV, BIOFLOW V and BIOSCIENCE) with 4480 patients showed a non-significant trend towards lower TLF in 
the Orsiro BP-SES. ${ }^{35}$ Third, it is important to note that the BIOSTEMI trial $(\mathrm{n}=1300)$ incorporated historical data of 407 patients with acute STEMI from the BIOSCIENCE trial and these patients could not be excluded from analysis in both data sets. Fourth, while our study demonstrated low heterogeneity when comparing clinical outcomes $\left(I^{2}=29 \%\right)$, there was lack of uniform data and reporting between the trials. Specifically, one study (PRISON IV) did not report TLF and our direct approach to the corresponding author for this information did not receive a response and hence this trial was not eligible forthe primary endpoint analysis. Fifth, although we performed a meta-regression on ACS status of participants, clinical events were infrequent in all studies, and hence caution should be applied when comparing subgroups. Finally, the absolute difference is small, with large numbers of patients needed to treat. These may be offset by real life challenges of the ultra-thin strut stent platforms including limited radiographic visibility and reduced radial stregnth and maximum diameter stent expansion limits.

\section{CONCLUSION}

In this meta-analysis comparing modern generation DES platforms, patients randomly assigned to PCI with the ultrathin-strut biodegradable polymer stent (Orsiro) had reduced risk of target lesion failure compared with contemporary durable polymer DES with thicker stent struts at mean follow-up of 2.8 years. This benefit was largely driven by reduced target vessel myocardial infarction and supports the clinical utility of ultra-thin strut stent designs. Additional well powered randomised clinical trials with long-term follow-up are required to compare modern generation stent platforms focusing on different patient subgroups including small-vessel disease and acute coronary syndromes.

Acknowledgements We acknowledge the support of Bets Conway and her team of research nurses at Gosford hospital. We pay credit to the researchers and patients involved in the trials incorporated in this study.

Contributors MRM contributed to study design, wrote the first draft and performed the statistical analysis. MRM, PB and CFS performed the systematic review. CFS and PB edited the manuscript. MRM and RS extracted the data for analysis. TF checked the data and provided consensus. CFS and MP performed the risk of bias analysis and TF provided consensus. TF devised the study, performed literature review, critically appraised and edited the manuscript.

Funding The authors have not declared a specific grant for this research from any funding agency in the public, commercial or not-for-profit sectors.

Competing interests None declared.

Patient consent for publication Not required.

Ethics approval Ethics approval was not applicable for this secondary pooled analysis.

Provenance and peer review Not commissioned; externally peer reviewed.

Data availability statement All data is all available within this manuscript. Methods registered online with PROSPERO (CRD42019147136).

Open access This is an open access article distributed in accordance with the Creative Commons Attribution Non Commercial (CC BY-NC 4.0) license, which permits others to distribute, remix, adapt, build upon this work non-commercially, and license their derivative works on different terms, provided the original work is properly cited, appropriate credit is given, any changes made indicated, and the use is non-commercial. See: http://creativecommons.org/licenses/by-nc/4.0/.

\section{ORCID iDs}

Mohammad Riashad Monjur http://orcid.org/0000-0003-1493-953X

Thomas Ford http://orcid.org/0000-0003-4009-6652

\section{REFERENCES}

1 Canfield J, Totary-Jain H. 40 years of percutaneous coronary intervention: history and future directions. J Pers Med 2018;8:33.

2 Newsome LT, Kutcher MA, Royster RL. Coronary artery stents: Part I. evolution of percutaneous coronary intervention. Anesth Analg 2008;107:552-69.

3 Bangalore S. The elusive late benefit of biodegradable polymer drugeluting stents. Circulation 2019;139:334-6.

4 Lee D-H, de la Torre Hernandez JM. The newest generation of drugeluting stents and beyond. Eur Cardiol 2018;13:54-9.

5 Bangalore S, Toklu B, Patel N, et al. Newer-Generation ultrathin strut drug-eluting stents versus older second-generation Thicker strut drug-eluting stents for coronary artery disease. Circulation 2018;138:2216-26.

6 Lipinski MJ, Forrestal BJ, lantorno M, et al. A comparison of the ultrathin Orsiro hybrid sirolimus-eluting stent with contemporary drug-eluting stents: a meta-analysis of randomized controlled trials. Cardiovasc Revasc Med 2018;19:5-11.

7 Zhu P, Zhou X, Zhang C, et al. Safety and efficacy of ultrathin strut biodegradable polymer sirolimus-eluting stent versus durable polymer drug-eluting stents: a meta-analysis of randomized trials. BMC Cardiovasc Disord 2018;18:170.

8 Cassese S, Ndrepepa G, Byrne RA, et al. Outcomes of patients treated with ultrathin-strut biodegradable polymer sirolimuseluting stents versus fluoropolymer-based everolimus-eluting stents: a meta-analysis of randomised trials. Eurolntervention 2018:14:224-31.

9 Kandzari DE, Koolen JJ, Doros G, et al. Ultrathin Bioresorbable polymer sirolimus-eluting stents versus thin durable polymer everolimus-eluting stents. J Am Coll Cardiol 2018;72:3287-97.

10 Iglesias JF, Muller O, Heg D, et al. Biodegradable polymer sirolimuseluting stents versus durable polymer everolimus-eluting stents in patients with ST-segment elevation myocardial infarction (BIOSTEMI): a single-blind, prospective, randomised superiority trial. Lancet 2019;394:1243-53

11 Moher D, Liberati A, Tetzlaff J, et al. Preferred reporting items for systematic reviews and meta-analyses: the PRISMA statement. BMJ 2009;339:b2535.

12 Sterne JAC, Sutton AJ, loannidis JPA, et al. Recommendations for examining and interpreting funnel plot asymmetry in meta-analyses of randomised controlled trials. BMJ 2011;343:d4002.

13 Garcia-Garcia HM, McFadden EP, Farb A, et al. Standardized end point definitions for coronary intervention trials: the academic research Consortium-2 consensus document. Eur Heart $J$ 2018;39:2192-207.

14 Viechtbauer W. Conducting Meta-Analyses in $R$ with the metafor Package. J Stat Softw 2010;36:48.

15 Higgins JPT, Thompson SG, Deeks JJ, et al. Measuring inconsistency in meta-analyses. BMJ 2003;327:557-60.

16 Wetterslev J, Jakobsen JC, Gluud C. Trial sequential analysis in systematic reviews with meta-analysis. BMC Med Res Methodol 2017;17:39.

17 Buiten RA, Ploumen EH, Zocca P, et al. Thin, very thin, or ultrathin strut biodegradable or durable polymer-coated drug-eluting stents: 3-year outcomes of BIO-RESORT. JACC Cardiovasc Interv 2019;12:1650-60.

18 Lefèvre T, Haude M, Neumann F-J, et al. Comparison of a Novel Biodegradable Polymer Sirolimus-Eluting Stent With a Durable Polymer Everolimus-Eluting Stent: 5-Year Outcomes of the Randomized BIOFLOW-II Trial. JACC Cardiovasc Interv 2018;11:995-1002.

19 Pilgrim T, Piccolo R, Heg D, et al. Ultrathin-strut, biodegradablepolymer, sirolimus-eluting stents versus thin-strut, durablepolymer, everolimus-eluting stents for percutaneous coronary revascularisation: 5-year outcomes of the bioscience randomised trial. Lancet 2018;392:737-46.

20 Saito S, Toelg R, Witzenbichler B, et al. BIOFLOW-IV, a randomised, intercontinental, multicentre study to assess the safety and effectiveness of the Orsiro sirolimus-eluting stent in the treatment of subjects with de novo coronary artery lesions: primary outcome target vessel failure at 12 months. Eurolntervention 2019;15:e1006-13. 
21 Teeuwen K, van der Schaaf RJ, Adriaenssens T, et al. Randomized Multicenter Trial Investigating Angiographic Outcomes of Hybrid Sirolimus-Eluting Stents With Biodegradable Polymer Compared With Everolimus-Eluting Stents With Durable Polymer in Chronic Total Occlusions: The PRISON IV Trial. JACC Cardiovasc Interv 2017;10:133-43.

22 von Birgelen C, Zocca P, Buiten RA, et al. Thin composite wire strut, durable polymer-coated (Resolute Onyx) versus ultrathin cobaltchromium strut, bioresorbable polymer-coated (Orsiro) drug-eluting stents in allcomers with coronary artery disease (BIONYX): an international, single-blind, randomised non-inferiority trial. Lancet 2018;392:1235-45.

$23 \mathrm{Kim}$ S-H, Kang S-H, Lee JM, et al. Three-Year clinical outcome of biodegradable hybrid polymer Orsiro sirolimus-eluting stent and the durable biocompatible polymer Resolute integrity zotarolimus-eluting stent: a randomized controlled trial. Catheter Cardiovasc Interv 2019. doi:10.1002/ccd.28654. [Epub ahead of print: 20 Dec 2019].

24 Kandzari DE, Koolen JJ, Doros G, et al. Ultrathin BioresorbablePolymer sirolimus-eluting stents versus thin Durable-Polymer everolimus-eluting stents for coronary revascularization: 3-year outcomes from the randomized BIOFLOW V trial. JACC Cardiovasc Interv 2020;13:1343-53.

25 Buiten RA, Ploumen EH, Zocca P, et al. Thin Composite-WireStrut zotarolimus-eluting stents versus Ultrathin-Strut sirolimuseluting stents in BIONYX at 2 years. JACC Cardiovasc Interv 2020;13:1100-9.

26 Li C, Yang Y, Han Y, et al. Comparison of the ultrathin strut, biodegradable polymer sirolimus-eluting stent with a durable polymer everolimus-eluting stent in a Chinese population: the randomized BIOFLOW VI trial. Clin Ther 2020;42:649-60.

27 Kutcher MA. Biodegradable-Polymer Drug-Eluting Stent Platforms: The Importance of Long-Term Outcomes. JACC Cardiovasc Interv 2018;11:1003-5.
28 Kolandaivelu K, Swaminathan R, Gibson WJ, et al. Stent thrombogenicity early in high-risk interventional settings is driven by stent design and deployment and protected by polymer-drug coatings. Circulation 2011;123:1400-9.

29 Ford TJ, Berry C, De Bruyne B, et al. Physiological Predictors of Acute Coronary Syndromes: Emerging Insights From the Plaque to the Vulnerable Patient. JACC Cardiovasc Interv 2017;10:2539-47.

30 Cassese S, Lahmann AL, Joner M. Ultrathin strut biodegradablepolymer sirolimus-eluting stents: being wary or going with the flow? $J$ Thorac Dis 2018;10:688-92.

31 Bangalore S, Toklu B, Amoroso N, et al. Bare metal stents, durable polymer drug eluting stents, and biodegradable polymer drug eluting stents for coronary artery disease: mixed treatment comparison meta-analysis. BMJ 2013;347:f6625.

32 Kirtane AJ. Off script: after ischemia, the devil is in the (design) details, 2019. Available: https://www.tctmd.com/news/script-afterischemia-devil-design-details [Accessed 29 Nov 2019].

33 Lansky AJ, Stone GW. Periprocedural myocardial infarction: prevalence, prognosis, and prevention. Circ Cardiovasc Interv 2010;3:602-10.

34 Kawamoto H, Panoulas VF, Sato K, et al. Impact of strut width in periprocedural myocardial infarction: a Propensity-Matched comparison between Bioresorbable scaffolds and the firstgeneration sirolimus-eluting stent. JACC Cardiovasc Interv 2015;8:900-9.

35 Pilgrim T, Rothenbühler M, Siontis GCM, et al. 100.62 Ultrathin-Strut Biodegradable-Polymer sirolimus-eluting stents versus Thin-Strut Durable-Polymer everolimus-eluting stents in patients undergoing percutaneous coronary intervention: a meta-analysis of individual patient data from randomized controlled trials. JACC Cardiovasc Interv 2019;12:S19-20. 